\title{
The bialaphos biosynthetic genes of Streptomyces viridochromogenes: cloning, heterospecific expression, and comparison with the genes of Streptomyces hygroscopicus
}

\author{
Osamu Hara, ${ }^{1}$ Takeshi Murakami, ${ }^{2}$ Satoshi Imai, ${ }^{1}$ Hiroyuki Anzai, ${ }^{1}$ Reiko Itoh, ${ }^{1}$ \\ Yoichi Kumada, ${ }^{1}$ Eriko Takano, ${ }^{1}$ Eriko Satoh, ${ }^{1}$ Atsuyuki SatoH, ${ }^{1}$ Kozo Nagaoka ${ }^{1}$ and \\ CHARLES THOMPSON ${ }^{3 *}$ \\ ${ }^{1}$ Pharmaceutical Research Center, Meiji Seika Kaisha, Ltd, Morooka-cho, Kohoku-ku, Yokohama, 222 Japan \\ ${ }^{2}$ Pharmaceutical Technology Laboratories, Meiji Seika Kaisha, Ltd, Kayama, Odawara, Kanagawa, 250-01, Japan \\ ${ }^{3}$ Unité de genie microbiologique, Institut Pasteur, 25 et 28 rue du Docteur Roux, 75724 Paris Cedex 15, France
}

(Received 21 June 1990; revised 15 October 1990; accepted 23 October 1990)

\begin{abstract}
The bialaphos resistance gene, bar, was used as a selectable marker to isolate the bialaphos production genes (bap) from the Streptomyces viridochromogenes genome. The $S$. viridochromogenes bar gene was cloned on overlapping restriction fragments using pIJ680 and pIJ702 in the bialaphos-sensitive host, S. lividans. Although the restriction endonuclease cleavage map of these fragments was not similar to the bap cluster of $S$. hygroscopicus, the presence and location of bar and four other bap genes as well as a gene required for the transcriptional activation of the cluster $(\operatorname{brp} A)$ was demonstrated by heterologous cloning experiments using a series of previously characterized bialaphos-nonproducing $S$. hygroscopicus mutants. Since recombination-deficient mutants of streptomycetes have not been isolated, restored function provided by cloned homologous DNA results from both recombination (marker rescue) and complementation in trans. In contrast to our previously reported homologous cloning experiments where we were able to define the position of mutant alleles by recombination, in these heterologous cloning experiments we observed little if any recombination between plasmid-cloned genes and the chromosome. As a result, this approach allowed us to define the location and orientation of functional genes using a genetic complementation test. The organization of the clustered $S$. viridochromogenes bap genes was indistinguishable from the corresponding $S$. hygroscopicus mutant alleles. The fact that the $S$. viridochromogenes transcriptional regulatory gene, brp $A$, functioned in $S$. hygroscopicus implied that some transcriptional regulatory signals may also be interchangeable. In these two Streptomyces species, which have considerable nucleotide sequence divergence, the complex biochemical and genetic organization of the bialaphos biosynthetic pathway is conserved.
\end{abstract}

\section{Introduction}

The observation that the production of a given antibiotic is strain- rather than species-dependent suggests that antibiotic biosynthetic genes may be horizontally transmissible. Questions of whether taxonomically different organisms which make the same antibiotic employ similar genes and biosynthetic pathways are only now beginning to be addressed. Streptomycin is produced by many species of Streptomyces including $S$. griseus and $S$. glaucescens. Nucleotide sequence analysis of the streptomycin phosphotransferase genes found in these strains has shown that they are $75 \%$ identical

Abbreviations: DPAT, demethylphosphinothricin acetyltransferase; NP, nonproducing (see also legend to Fig. 1).
(Distler et al., 1987; Vögtli \& Hütter, 1987). Genes isolated from different species of Streptomyces which encode enzymes for corresponding steps in the biosynthesis of different polyketide antibiotics are also similar (Bibb et al., 1989; Sherman et al., 1989). Even more strikingly, genes encoding $\beta$-lactam production in prokaryotic actinomycetes and eukaryotic fungi are closely related (Smith et al., 1990). In streptomycetes, genes which encode enzymes for the biosynthesis of a given antibiotic are found in clusters (Chater \& Bruton, 1985; Malpartida \& Hopwood, 1984; Murakami et al., 1986; Seno \& Baltz, 1989). We have focussed our studies on genes required for the biosynthesis of bialaphos, an antibiotic produced by $S$. hygroscopicus and $S$. viridochromogenes. 
Bialaphos is a tripeptide which is composed of two Lalanine residues and the glutamic acid analogue, phosphinothricin (Bayer et al., 1972; Kondo et al., 1973). A similar tripeptide antibiotic, phosalacin, containing Lalanine, L-leucine and phosphinothricin, is produced by the actinomycete Kitasatosporia phosalacinea (Omura et al., 1984).

$S$. hygroscopicus bialaphos biosynthetic genes have been cloned and mapped in a cluster which also contains the bialaphos resistance gene, bar (Hara et al., 1988; Murakami et al., 1986). The pathway for bialaphos antibiotic production in $S$. hygroscopicus has been determined largely by analysing products that are accumulated and converted by a series of nonproducing mutants (NP; see Fig. 1). The bar gene product, demethylphosphinothricin acetyltransferase (DPAT), catalyses the acetylation of both phosphinothricin and demethylphosphinothricin, an intermediate in the pathway (Kumada et al., 1988; Thompson et al., 1987). Thus DPAT functions both as an integral part of the biosynthetic pathway and as an enzyme which confers antibiotic resistance (Kumada et al., 1988). A gene which is required for the transcription of bialaphos biosynthesis genes $(b r p A)$ is found at one extremity of the bialaphos antibiotic production (bap) gene cluster (Anzai et al., 1987). Genetic clustering of bap genes in S. hygroscopicus near bar suggested that the corresponding $S$. viridochromogenes bar gene (pat; Strauch et al., 1988; we chose to use the original name bar here in referring to this gene in both clusters) which has been cloned might be used as a selectable marker to isolate restriction fragments containing the corresponding $S$. viridochromogenes bap genes. These restriction fragments might then be used to compare the organization and regulation of bap genes in the two organisms.

\section{Methods}

Bacterial strains. S. viridochromogenes JCM4977, obtained from the Japan Collection of Micro-organisms is the same as $S$. viridochromogenes Tü494 (Bayer et al., 1972). S. hygroscopicus bialaphos nonproducing (NP) strains NP8 (Imai et al., 1985), NP44 (Shimotohno et al., 1986), NP45 (Imai et al., 1985), NP46 (Imai et al., 1984), NP47 (Imai et al., 1984), NP57 (Anzai et al., 1987), NP213 (Seto et al., 1983a) and NP221 (Imai et al., 1984), derivatives of S. hygroscopicus ATCC 21705 (Kondo et al., 1973), were obtained from the Meiji Seika Kaisha Culture Collection. bap mutations were assigned the same allele numbers as the NP mutant strains in which they were found. $S$. lividans 66 (Lomovskaya et al., 1972) was obtained from the John Innes Culture Collection.

Media. Minimal medium (Thompson et al., 1987), A4 bialaphos production medium (Ogawa et al., 1983b), and bialaphos assay medium (Murakami et al., 1986) have been described.

DNA manipulations and transformation. S. viridochromogenes bap genes were isolated and analysed using the recombinant DNA techniques previously used for the isolation and study of $S$. hygroscopicus bap genes (Hopwood et al., 1985; Murakami et al., 1986). All cloning experiments were done with plasmids pIJ486 (Ward et al., 1986), pIJ680 (Hopwood et al., 1985) or pIJ702 (Katz et al., 1983) (Fig. 2) obtained from the John Innes Culture Collection. The $S$. viridochromogenes bar gene was isolated from a genomic library prepared in $S$. lividans by replica plating the regeneration plates to minimal medium containing $50 \mu \mathrm{g}$ thiostrepton $\mathrm{ml}^{-1}$ and $100 \mu \mathrm{g}$ bialaphos $\mathrm{ml}^{-1}$ (Murakami et al., 1986). S. viridochromogenes bap genes were subcloned in $S$. lividans and then introduced into $S$. hygroscopicus NP mutants by transformation.

Assay of bap gene expression in $S$. hygroscopicus and $S$. lividans. Expression of cloned $S$. viridochromogenes bap genes was assayed in either $S$. hygroscopicus NP mutants or $S$. lividans. $S$. hygroscopicus strains containing cloned bap genes were inoculated onto agar plugs containing A4 medium (Ogawa et al., 1983b) and grown for $5 \mathrm{~d}$ at $28^{\circ} \mathrm{C}$. The plugs were transferred to the surface of bialaphos assay medium seeded with lawns of the bialaphos-sensitive indicator bacterium, Bacillus subtilis ATCC 6633. Bialaphos production was detected as a zone of growth inhibition. Expression of cloned bap genes in $S$. lividans was done using a co-synthesis test in which $S$. lividans strains containing cloned bap genes were co-cultivated on agar plugs with $S$. hygroscopicus NP mutants as described above. Bialaphos production was detected by bioassay as described above.

Assay for bialaphos resistance. Bialaphos resistance in S. lividans transformants was assayed by inoculating spores on minimal medium containing $100 \mu \mathrm{g}$ bialaphos $\mathrm{ml}^{-1}$.

\section{Results}

\section{Cloning of the bialaphos resistance gene}

$S$. viridochromogenes JCM4977 genomic DNA was cleaved with either BamHI, Pst I or KpnI and ligated to pIJ680, or partially cleaved with $S p h I$ and ligated to pIJ702. These ligation mixes were used to transform the bialaphos-sensitive host, $S$. lividans. In this way, plasmids were isolated which conferred resistance to bialaphos (Fig. 3) and presumably carried the bar gene.

These included two plasmids which contained multiple BamHI fragments. Since they both had the same $4.3 \mathrm{~kb}$ insert, this fragment was subcloned in both orientations in pIJ680 to generate pMSB401 and pMSB402. The restriction map of this BamHI fragment showed that it was the same as that previously cloned (Strauch et al., 1988).

In addition, 16 independently isolated plasmids containing KpnI fragments were analysed; all contained identical $9.5 \mathrm{~kb}$ inserts. Plasmids pMSB53-1 and pMSB53-3, which contained this fragment cloned in opposite orientations, were chosen for further study.

Two bialaphos-resistant clones each containing an insert of a $7.3 \mathrm{~kb}$ Pst I fragment were isolated. This fragment was subcloned in pIJ 680 in both orientations to generate pMSB403 and pMSB404.

One bialaphos-resistant clone was isolated from the gene bank generated by partial $S p h \mathrm{I}$ digestion. This plasmid, pMSB52-1, had three SphI fragments, of 7.5, $1 \cdot 6$ and $1.4 \mathrm{~kb}$. 

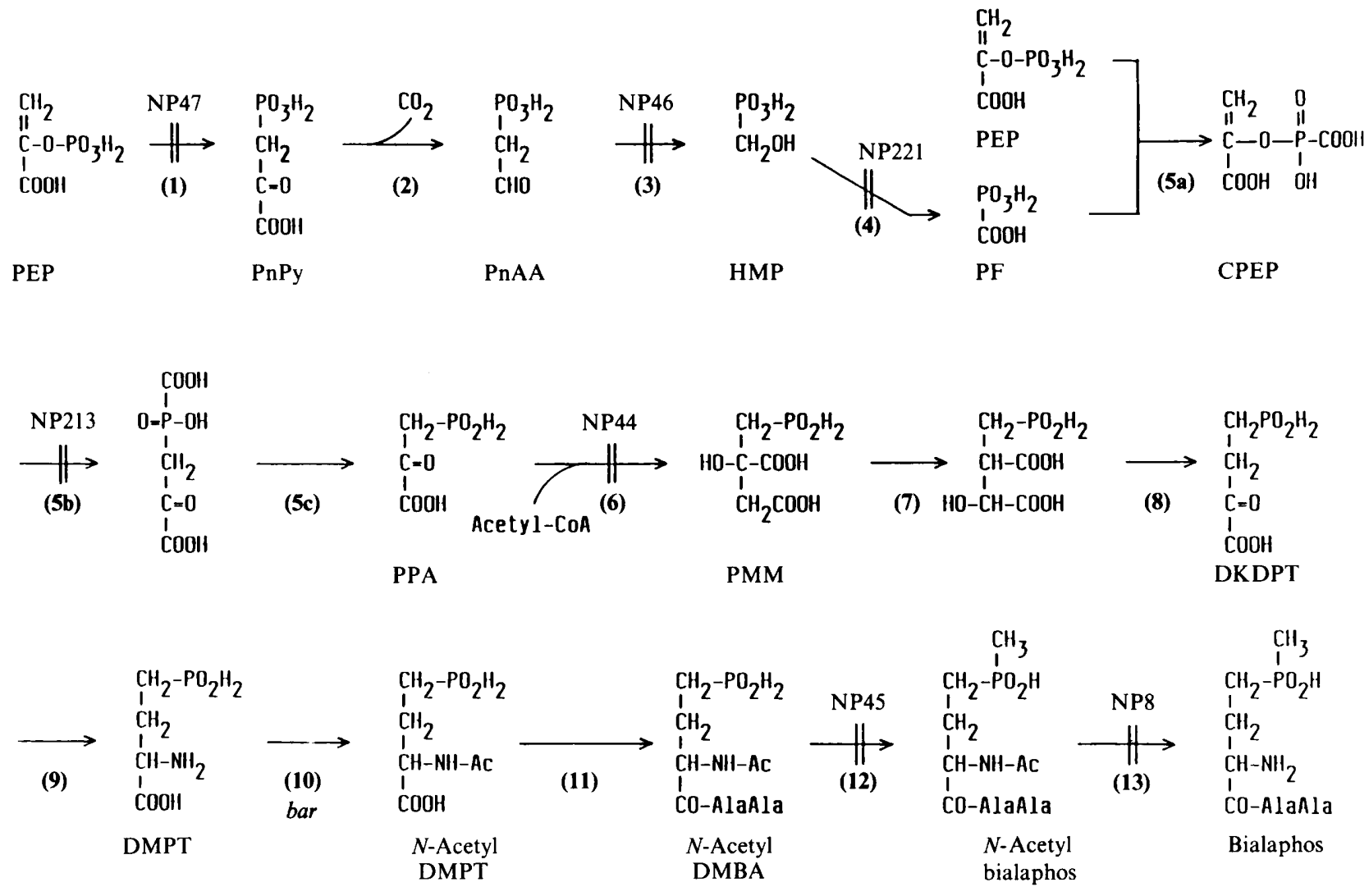

Fig. 1. The biosynthesis of bialaphos. $S$. hygroscopicus mutants which define steps $1,3,4,5,6,12$ and 13 were used here to study $S$. viridochromogenes bap genes. The pathway shown is based on the work from the laboratories of H. Seto and S. Imai (Hidaka et al., 1989 ; Imai et al., 1984, 1985; Seto et al., 1983a, b, 1984; Shimotohno et al., 1986). NP mutants which define steps 1-13 are indicated. PEP, phosphoenolpyruvic acid; PnPy, phosphonopyruvic acid; PnAA, phosphonoacetaldehyde; HMP, hydroxymethylphosphonic acid; PF, phosphonoformic acid; CPEP, carboxyphosphoenolpyruvic acid; PPA, phosphinopyruvic acid; PMM, phosphinomethylmalic acid; DKDPT, deamino- $\alpha$-ketodemethylphosphinothricin; DMPT, demethylphosphinothricin; DMBA, demethybialaphos.
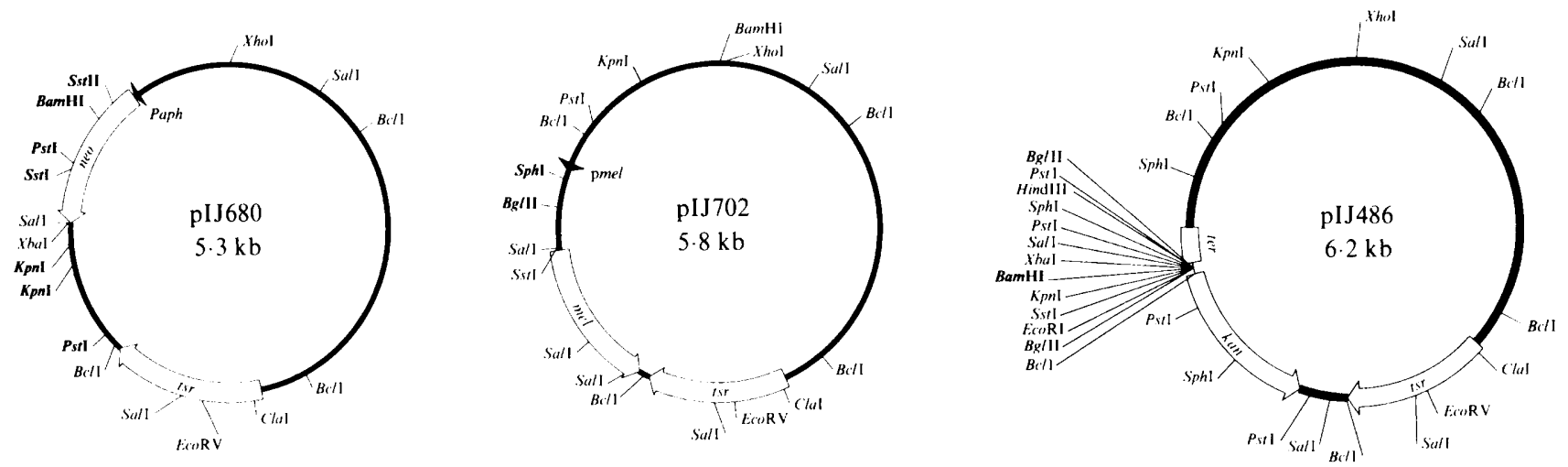

Fig. 2. Physical maps of vectors pIJ680, pIJ702 and pIJ486. Sites used in cloning experiments described in the text are enlarged. mel, a gene encoding tyrosinase which allows for the synthesis of melanin; neo, the $S$. fradiae neomycin resistance gene; kan, kanamycin resistance gene from $\operatorname{Tn} 5$; tsr, thiostrepton resistance gene from $S$. azureus. Filled arrows indicate promoters: paph, aminoglycoside phosphotransferase promoter (Janssen et al., 1989); pmel, melanin promoter (Leu et al., 1989). 


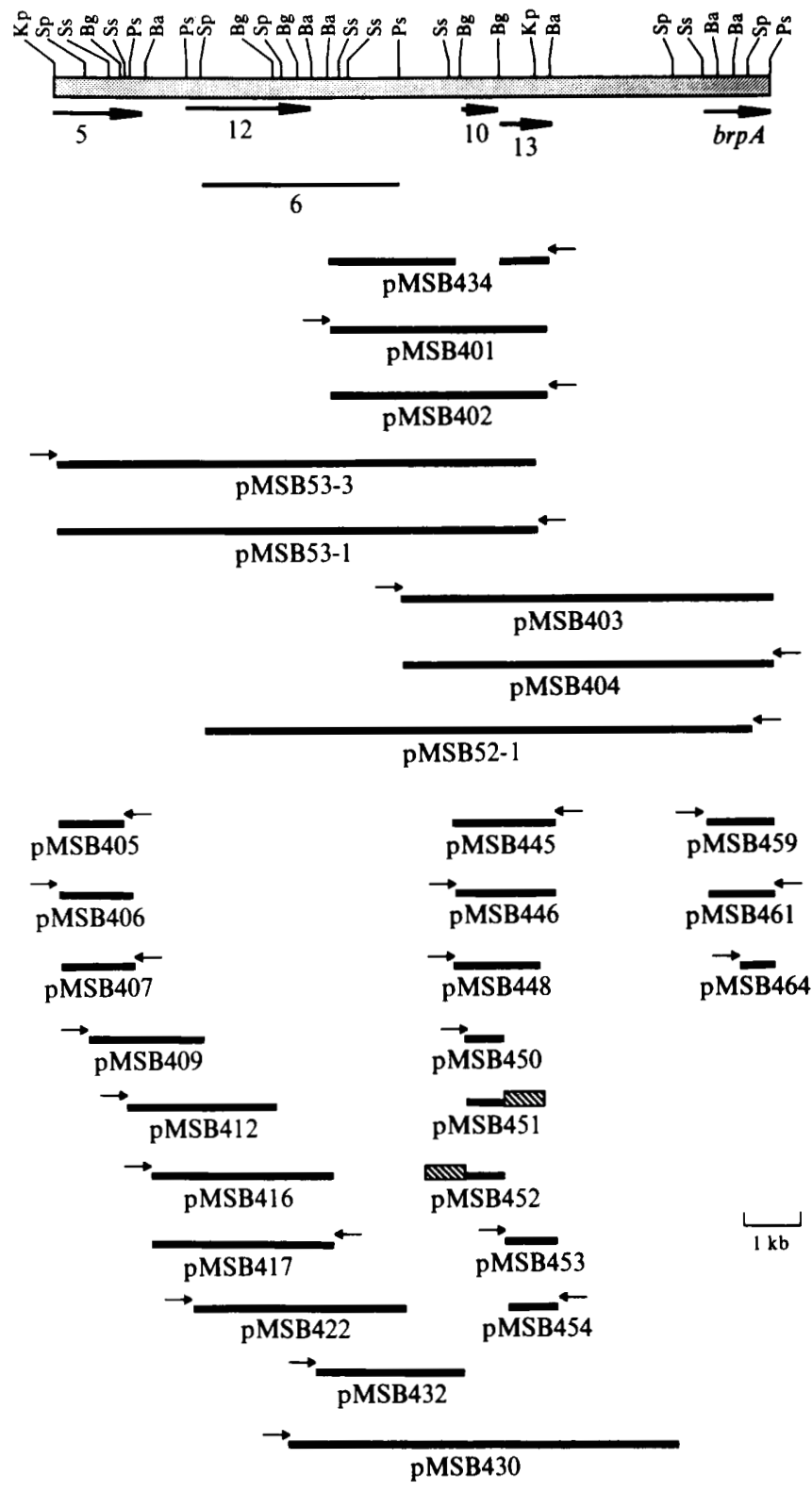

Fig. 3. The bap gene cluster in $S$. viridochromogenes. The location of $S$. viridochromogenes cloned fragments which restore productivity to $S$. hygroscopicus blocked mutants is shown. Small arrows adjacent to the cloned fragments indicate the direction of vector promoters with respect to the cloned fragment. Larger arrows below the physical map indicate the positions and orientations of bap genes (based on results shown in Table 1). Numbers below the arrows indicate the step of the biosynthetic pathway (Fig. 1) which is catalysed by the product of the cloned gene. kan, kanamycin resistance gene of Tn5. Restriction enzymes: Ba, BamHI ; Bg, BglII ; Kp, KpnI ; Ps, PstI ; Sp, SphI ; Ss, SstI All subclones were derived from pMSB52-1, pMSB53-1, pMSB401, pMSB402, pMSB403 or pMSB404. With the exception of pMSB406, pMSB407, pMSB445, pMSB446, pMSB459 and pMSB461, subcloning of single fragments was done using restriction sites located within the cloned fragments by complete digestion of donor plasmid and recipient vector. pMSB406 and pMSB407 were derived from pMSB53-1 by subcloning a PstI fragment generated by cleavage at the upstream Pst $\mathrm{I}$ site in the neo gene of the vector (Fig. 2) and the proximal PstI site in the cloned fragment. This fragment was cloned in both orientations into
The restriction maps of all of the plasmids described above overlapped with each other as shown and thus allowed us to define the restriction endonuclease cleavage map of the entire region as shown in Fig. 3.

Genetic linkage of the bialaphos biosynthesis genes and the bialaphos resistance gene

Functional analyses of $S$. viridochromogenes bialaphos biosynthetic genes were carried out as described by Murakami et al. (1986) using the $S$. hygroscopicus NP mutants listed in Table 1. Plasmids pMSB53-1 and pMSB53-3 restored productivity to NP213 (step 5 defect), NP44 (step 6 defect) and NP8 (step 13 defect). However, these plasmids did not restore productivity to any other mutants including NP47 (step 1 defect), NP46 (step 3 defect), NP221 (step 4 defect), NP45 (step 12 defect) and NP57 (defective for the regulatory gene brpA). Plasmid pMSB52-1 was able to restore productivity to NP44 and NP8, but not to NP213, NP45 or NP57. Plasmids pMSB401 and pMSB402 restored productivity only to NP8. Plasmids pMSB403 and pMSB404 were able to restore productivity to NP8 and NP57. In summary, plasmids containing primary clones of overlapping restriction fragments of $S$. viridochromogenes DNA linked to bar were able to complement $S$. hygroscopicus mutants defective in several genes encoding enzymic (steps 5, 6 and 13) or regulatory ( $b r p A)$ proteins and carried the step 12 gene whose expression was not detected (see below).

\section{Localization of individual genes and promoter sequences}

Subcloning experiments defined more precisely the position of individual bap genes and suggested the location of regions having transcriptional activity (described below, in Fig. 3 and in Table 1). Genes inserted into the mel or neo genes in the vectors $\mathrm{pIJ} 702$ and pIJ680 can be directed by the aph (Janssen et al., 1989) or mel (Leu et al., 1989) promoters (Fig. 2).

The location of the step 5 structural gene was indicated by the observation that both pMSB406 and pMSB407 restored productivity to NP213. The fact that the level of productivity was markedly higher in NP213(pMSB406) or NP213(pMSB53-3) compared to NP213(pMSB407) or

pIJ680 cleaved with PstI. pMSB445 was derived from pMSB402 by subcloning an $S s t \mathrm{I}$ fragment generated by cleavage at the upstream $S s t \mathrm{I}$ site in the neo gene of the vector (Fig. 2) and the proximal SstI site in the cloned fragment. This fragment was cloned into the $S s t \mathrm{I}$ sites in the neo gene of pIJ680 in the orientation indicated to generate pMSB445. Similarly, pMSB446 was derived from pMSB401 by cleavage at the downstream SstI site in neo and the proximal Sst $\mathrm{I}$ site in the cloned fragment. pMSB459 and pMSB461 were derived from pMSB403 and pMSB404 in the same way. 
Table 1. Gene expression from plasmids containing cloned bap genes

Key: - , no growth inhibition observed; + , zone of growth inhibition less than $20 \mathrm{~mm} ;++$, zone of growth inhibition greater than $20 \mathrm{~mm}$; bialaphos sensitive; $r$, bialaphos resistant. See Methods for details of the assays.

\begin{tabular}{|c|c|c|c|c|c|c|c|c|c|c|c|}
\hline \multirow[b]{2}{*}{ Plasmid } & \multirow[b]{2}{*}{ Vector } & \multirow[b]{2}{*}{$\begin{array}{l}\text { Fragment } \\
\text { cloned }^{*}\end{array}$} & \multicolumn{9}{|c|}{ Host (defect) $\dagger$} \\
\hline & & & $\begin{array}{l}\text { NP46 } \\
\text { (3) }\end{array}$ & $\begin{array}{l}\text { NP221 } \\
\text { (4) }\end{array}$ & $\begin{array}{c}\text { NP47 } \\
\text { (1) }\end{array}$ & $\begin{array}{l}\text { NP213 } \\
\text { (5) }\end{array}$ & $\begin{array}{c}\text { NP45 } \\
\text { (12) }\end{array}$ & $\begin{array}{l}\text { NP44 } \\
\text { (6) }\end{array}$ & $\begin{array}{c}1326 \ddagger \\
(\text { bar })\end{array}$ & $\begin{array}{l}\text { NP8 } \\
(13)\end{array}$ & $\begin{array}{l}\text { NP57 } \\
(\text { brpA })\end{array}$ \\
\hline pMSB53-1 & pIJ680 & KpnI & - & - & - & + & - & $+t$ & $\mathbf{r}$ & + & - \\
\hline pMSB53-3 & pIJ680 & KpnI & - & - & - & $+t$ & - & $+t$ & $\mathrm{r}$ & + & - \\
\hline pMSB52-1 & pIJ702 & $S p h \mathrm{I}$ & & & & - & - & $+t$ & $\mathbf{r}$ & $+t$ & - \\
\hline pMSB401 & pIJ680 & BamHI & & & & - & - & - & $r$ & ++ & - \\
\hline pMSB402 & pIJ680 & Bam HI & & & & - & - & - & $r$ & $+t$ & - \\
\hline pMSB403 & pIJ680 & Pst I & & & & - & - & - & $\mathbf{r}$ & ++ & $+t$ \\
\hline pMSB404 & pIJ680 & Pst I & & & & - & - & - & $\mathrm{r}$ & ++ & $+t$ \\
\hline pMSB405 & pIJ680 & $K p n \mathbf{I} / B g l \mathrm{II}$ & & & & - & & & & & \\
\hline pMSB406 & pIJ680 & KpnI/Pst I & & & & ++ & & & & & \\
\hline pMSB407 & pIJ680 & KpnI/Pst I & & & & + & & & & & \\
\hline pMSB409 & pIJ702 & $S p h \mathrm{I}$ & & & & - & & & & & \\
\hline pMSB412 & pIJ680 & BglII & & & & & - & & & & \\
\hline pMSB416 & pIJ680 & Bam HI & & & & & ++ & & & & \\
\hline pMSB417 & pIJ680 & Bam HI & & & & & - & & & & \\
\hline pMSB422 & pIJ680 & Pst I & & & & & ++ & $+t$ & & & \\
\hline pMSB430 & pIJ702 & SphI & & & & & & + & & & \\
\hline pMSB432 & pIJ680 & $B g l \mathrm{II}$ & & & & & & + & & & \\
\hline pMSB434 & pIJ680 & BamHI & & & & & & & $\mathbf{s}$ & + & \\
\hline pMSB445 & pIJ680 & Sst I/BamHI & & & & & & & $\mathbf{r}$ & ++ & \\
\hline pMSB446 & pIJ680 & Sst I/BamHI & & & & & & & r & ++ & \\
\hline pMSB448 & pIJ680 & Sst I/KpnI & & & & & & & $\mathrm{r}$ & + & \\
\hline pMSB450 & pIJ680 & $B g l$ II & & & & & & & $\mathrm{r}$ & - & \\
\hline pMSB451 & pIJ486 & $B g l$ II & & & & & & & $\mathbf{r}$ & & \\
\hline pMSB452 & pIJ486 & BglII & & & & & & & $r$ & & \\
\hline pMSB453 & pIJ680 & BglII/BamHI & & & & & & & s & ++ & \\
\hline pMSB454 & pIJ680 & BglII/BamHI & & & & & & & $\mathbf{s}$ & + & \\
\hline pMSB459 & pIJ680 & Sst I/Pst I & & & & & & & & & ++ \\
\hline pMSB461 & pIJ680 & Sst I/Pst I & & & & & & & & & - \\
\hline pMSB464 & pIJ680 & BamHI/Pst I & & & & & & & & & - \\
\hline
\end{tabular}

* Sites which defined the ends of the cloned fragment in the genome.

$\dagger$ Numbers in parentheses indicate blocked steps in the biosynthetic pathway shown in Fig. 1.

$\ddagger 1326=S$. lividans 66 , sensitive to bialaphos.

NP213(pMSB53-1) indicated that the cloned gene could be expressed from the aph promoter and that its orientation was as shown in Fig. 3. Although pMSB405 and pMSB409 had fragments which overlapped with each other as well as with pMSB406 and pMSB407, neither one of these plasmids restored productivity to NP213 (i.e. by recombination).

In spite of the fact that none of the primary clones described above could restore productivity to NP45 (defective for the step 12 structural gene), subcloning experiments revealed that the gene was present but not being expressed from pMSB53-1, pMSB53-3 or pMSB52-1. The observation that subcloning a $3.3 \mathrm{~kb}$ $B a m \mathrm{HI}$ fragment allowed production in one orientation (pMSB416) but not in the other (pMSB417) established the directionality and approximate position of the gene. The fact that pMSB422 also allowed production further localized the gene (Fig. 3).
pMSB430 and pMSB432 were only able to restore low levels of productivity in NP44 (step 6 defect) compared with pMSB52-1, pMSB53-3 and pMSB422. These observations suggested that restored productivity might be a result of recombination in a subpopulation of pMSB430 and pMSB432 transformants. To further examine this hypothesis, plasmids were tested for step 6 expression in $S$. lividans, a bialaphos nonproducing strain which presumably does not have a gene corresponding to step 6 . Crossfeeding tests between these transformants and NP44 indicated that pMSB52-1, pMSB53-3 and pMSB422 all expressed the step 6 enzyme in $S$. lividans while pMSB430 and pMSB432 did not. These results suggested that pMSB430 and pMSB432 did not contain the entire coding sequence. The smallest plasmid which could express a functional step 6 protein in $S$. lividans, pMSB422, defined the limits of the structural gene (Fig. 3). The location of bap-44 was 
revealed by overlaps of two subclones (pMSB422 and pMSB430) which could restore activity to NP44. Assuming that the bap-44 mutation was within the gene positioned it to the right of the step 12 gene as shown in Fig. 3.

Subcloning the bar gene gave results similar to that of Strauch et al. (1988). It was first localized by subcloning a $2.0 \mathrm{~kb}$ fragment in both orientations in pIJ680. $S$. lividans containing either of these plasmids (pMSB445, pMSB446) produced similar levels of DPPT activity (data not shown). Although the bar gene could be further subcloned on a $0.8 \mathrm{~kb} \mathrm{BglII}$ fragment (pMSB450), the levels of resistance were low. This fragment was cloned in both orientations in the promoter-probe vector, pIJ486 (plasmids pMSB451 and pMSB452). Only pMSB451 showed promoter activity in $S$. lividans as indicated by increased resistance to kanamycin. In $S$. hygroscopicus NP8, deletion of this fragment reduced expression of the step 13 gene (pMSB434).

A $1.0 \mathrm{~kb} \mathrm{BglII} /$ Bam $\mathrm{HI}$ fragment subcloned in pIJ680 (pMSB453, pMSB454) restored high-level productivity to NP8 (defective in step 13) only in one orientation (pMSB453). pMSB454 allowed low-level productivity. While pMSB402 restored high-level productivity to NP8, its activity was severely impaired by deletion of the internal BglII fragment (pMSB434). This observation indicated that the gene was read from its own promoter located on this $B g l \mathrm{II}$ fragment in the same direction as bar. Plasmids pMSB445 and pMSB446 contained a larger fragment which included the region having bar promoter activity and the step 13 gene cloned in alternative orientations. Since both orientations restored the same high level of production to NP8, the bar promoter probably allowed expression of the $S$. viridochromogenes step 13 gene in $S$. hygroscopicus.

Plasmids pMSB 459 and pMSB461 contained a $1 \cdot 1 \mathrm{~kb}$ fragment which could restore productivity to NP57 (brpA defective) in only one orientation. These data showed that $\operatorname{brp} A$ is read from left to right in the cluster. A plasmid containing a smaller subclone $(0.6 \mathrm{~kb})$ of the same region (pMSB464) failed to restore productivity.

In $S$. hygroscopicus, the bap cluster also contains genes corresponding to early steps in the pathway. These genes are contiguous and lie to the left of the step 5 gene. In order to determine whether $S$. viridochromogenes had a similar arrangement, adjacent DNA was isolated by cosmid cloning. Four clones which hybridized to pMSB53-3 were isolated. Southern blot analyses (data not shown) confirmed that these cosmids contained part of the KpnI fragment found in pMSB53-3 as well as DNA which hybridized to a plasmid which contained genes corresponding to steps 1, 3 and 4 (pMSB2-4; Murakami et al., 1986). These genes were in the same position as the corresponding genes in $S$. hygroscopicus.

\section{Discussion}

Although $S$. viridochromogenes and $S$. hygroscopicus are taxonomically distinct species isolated from different parts of the world, they produce the same antibiotic, bialaphos. We were interested in knowing whether the two species used the same biosynthetic pathway and, if so, whether the genetic organization and regulation of pathway enzymes were related. We therefore cloned $S$. viridochromogenes bap genes and have used them to study the function and organization of corresponding genes in S. hygroscopicus.

Genetic data presented here show that $S$. hygroscopicus and $S$. viridochromogenes employ similar if not identical pathway enzymes. In agreement with Strauch et al. (1988), we found that $S$. viridochromogenes has a bar gene similar to that found in $S$. hygroscopicus (Thompson et al., 1987) which encoded DPAT. More striking evidence for conservation of pathway enzymes was the fact that mutations in NP strains which have been used to define four steps in the $S$. hygroscopicus pathway could be complemented by $S$. viridochromogenes genes. In both species, all of these genes were closely linked to bar.

Subcloning experiments revealed that the distribution of genes in this cluster was identical in the two organisms (Fig. 4). Nevertheless, the restriction maps of the two bap clusters were quite different. Direct comparisons of the nucleotide sequences of cloned $b r p A$ genes revealed $30 \%$ mismatches and several minor deletions (A. Raibaud, R. Tizard \& C. Thompson, unpublished). Apparently, this divergence severely restricted recombination between cloned $S$. viridochromogenes DNA and the corresponding gene in the $S$. hygroscopicus chromosome.

In streptomycetes, restored function provided by cloned homologous DNA results from both recombination and complementation in trans (Murakami et al., 1986; Seno et al., 1984). We have previously shown that recombination which occurs between chromosome and plasmids containing homologous DNA makes it difficult to determine whether a plasmid restores wild-type phenotype by 'marker rescue' or by expression of the cloned gene (Murakami et al., 1986). In Escherichia coli, this complication can be avoided by doing such experiments in a recombination-deficient mutant. Although such $\operatorname{rec} A$ strains have not yet been isolated in streptomycetes, we have achieved a similar effect by subcloning $S$. viridochromogenes DNA in a heterologous host. Unlike homologous cloning as described above, the ability of cloned heterologous $S$. viridochromogenes fragments to restore antibiotic productivity usually depended on the presence of the entire gene corresponding to the mutant allele and often on expression from a vector promoter. However, an apparent exception to this rule should be noted. 

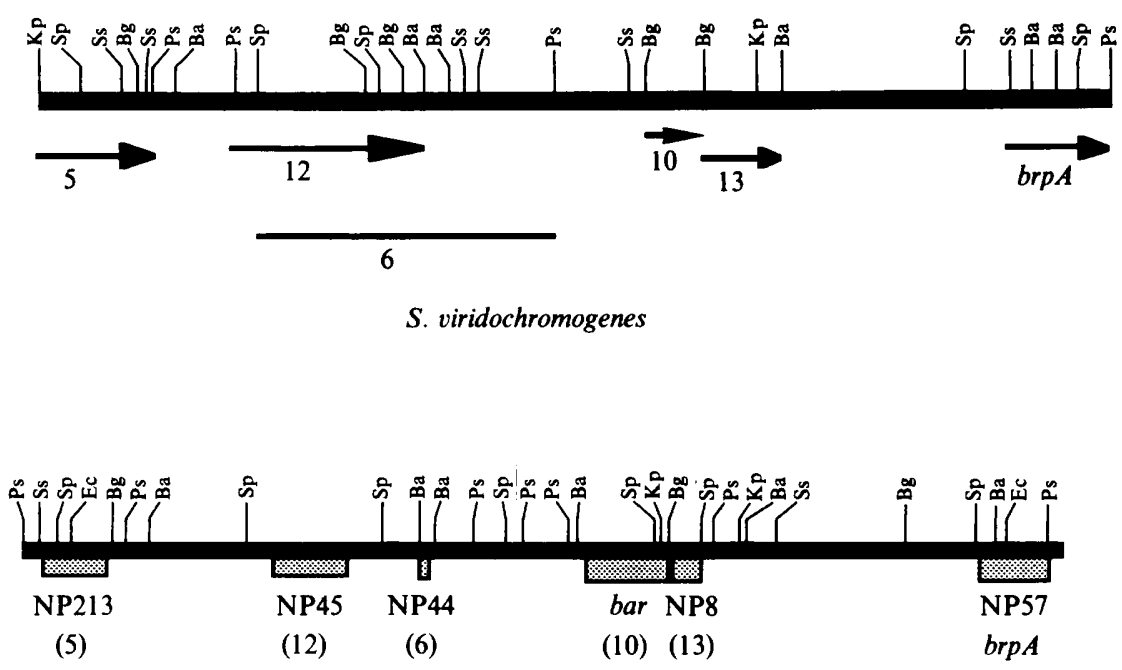

S. hygroscopicus

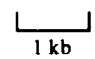

Fig. 4. Comparison of the $S$. viridochromogenes and $S$. hygroscopicus bap gene cluster. Abbreviations: Ec, EcoRI and as described in Fig. 1 and Fig. 3. Stippled bars indicate the limits of regions which can restore productivity by recombination (Murakami et al., 1986).

A defect in a chromosomal allele could be suppressed by an incomplete fragment of a cloned gene in one of three ways: activity of a chimeric fusion protein, intergenic recombination, or intragenic complementation. Low-frequency recombination between heterologous DNAs could explain the observation that several plasmids allowed step 6 activity in S. hygroscopicus NP44 but not in $S$. lividans, a strain which presumably does not contain an homologous gene. To determine whether interspecific recombination had taken place, it would be necessary to analyse the chromosomal DNA in NP44derived strains whose productivity had been restored by cloned DNA, but this is beyond the scope of the present study.

The fact that recombination, if occurring at all, gave only low levels of bap gene function also provided a means to assess the location of promoters. Although expression of a gene regardless of its orientation in the vector implied that the fragment contained a promoter, the present experiments were not designed to address this question; other experiments would be necessary to eliminate two other less likely possibilities. Sequences which do not serve as promoters on the chromosome might be able to initiate transcription when cloned on high-copy-number vectors. Secondly, the cloning sites used probably have some low-level transcriptional activity in the direction opposite to paph and pmel.

The step 12 function was not detected in any of the primary clones even though they did contain the entire coding sequence. Thus its native promoter in $S$. viridochromogenes was either not present on the plasmid or not functional in S. hygroscopicus. We prefer the latter hypothesis because the step 12 gene was apparently not expressed from the aph promoter located upstream even though it did allow expression of the step 5 gene. This suggested that a terminator (active in $S$. hygroscopicus) and a promoter (inactive in $S$. hygroscopicus) existed between genes for steps 5 and 12 . The step 12 gene was expressed only when this region was removed and the gene was cloned in one orientation downstream of the aph promoter.

That a promoter upstream of bar (also observed by Strauch et al., 1988) could also allow transcription of the step 13 gene was suggested by the observation that expression of these genes from pMSB445 and pMSB446 was orientation-independent in $S$. hygroscopicus. This promoter activity was mapped by deletion of an internal $B g l$ II fragment which reduced expression of the step 13 gene. This deleted fragment also showed promoter activity in $S$. lividans using the promoter-probe vector, pIJ486.

In $S$. hygroscopicus, transcriptional activation of the gene cluster requires the $b r p A$ regulatory gene. BrpA belongs to a family of transcriptional activators (Albright et al., 1989; Gross et al., 1989; Stock et al., 1990) and thus probably exerts its effect by interacting directly with bap gene promoters (C. Thomson, Raibaud and others, unpublished). Since BrpA from $S$. viridochromogenes activated transcription of $S$. hygroscopicus bap genes, these promoter sequences are presumably conserved. However, our observation that the $S$. viridochromogenes step 12 gene was not well expressed in $S$. hygroscopicus suggested that its promoter could not be activated and implied a species-specific mechanism. 
These studies describe the heterospecific expression of genes required to overcome defects in a previously established antibiotic biosynthetic pathway. Currently, there is interest in using this approach to create novel antibiotics either by diverting intermediates of one pathway into another or by modifying an endproduct. However, very little is known about how antibiotic biosynthesis genes are regulated in different species. The experiments described here underline the fact that heterologous expression is indeed a feasible objective, but that even closely related antibiotic biosynthetic gene clusters may have species-specific regulatory mechanisms and that subcloning individual genes in an expression vector may often be necessary.

In conclusion, despite considerable nucleotide sequence divergence in the bialaphos biosynthesis gene clusters found in two Streptomyces species, their biosynthetic pathways as well as their genetic organization and regulatory genes are very similar, suggesting that none of the bap genes are dispensable. The striking conservation of the arrangement of bap genes within each cluster might result from selective pressure for maintenance of a critical transcriptional structure. Alternatively, tight genetic linkage of these antibiotic biosynthesis genes may reflect their capacity to be transferred en bloc between different species of Streptomyces. Our studies underline the fact that recombination between different species of Streptomyces is limited by sequence divergence. We therefore suggest that the junctions between chromosomal and antibiotic biosynthetic gene clusters might include DNA sequences associated with genetic mobility in the absence of general recombination.

We wish to thank Yachiyo Yoshizawa for technical assistance and Julian Davies and Colin Stuttard for critical reading of the manuscript.

\section{References}

Albright, L. M., Huala, E. \& Ausubel, F. M. (1989). Prokaryotic signal transduction mediated by sensor and regulatory protein pairs. Annual Review of Genetics 23, 311-336.

anzai, H., Murakami, R., Imai, S., Satoh, A., Nagaoka, K. \& THOMPSON, C. J. (1987). Transcriptional regulation of bialaphos biosynthesis in Streptomyces hygroscopicus. Journal of Bacteriology 169, 3482-3488.

Bayer, E., Gugel, K. H., Hagele, K., Hagenmaier, H., Jessipow, S., KONING, W. A. \& ZAHNER, H. (1972). Stoffwechselprodukte von Mikroorganismen. Phosphinothricin und Phosphinothricyl-alanylalanine. Helvetica Chimica Acta 55, 224-239.

Bibi, M. J., Biro, S., Motamedi, H., Collins, J. F. \& Hutchinson, C. R. (1989). Analysis of the nucleotide sequence of the Streptomyces glaucescens $t c m I$ genes provides key information about the enzymology of polyketide biosynthesis. EMBO Journal 8, 2727-2736.

ChATER, K. F. \& BRUTON, C. J. (1985). Resistance, regulatory and production genes for the antibiotic methylenomycin are clustered. EMBO Journal 4, 1893-1897.
Distler, J., Ebert, A., Mansouri, K., Pissowotzki, K., Stockmann, M. \& Pipersberg, W. (1987). Gene cluster for streptomycin biosynthesis in Streptomyces griseus: nucleotide sequence of three genes and analysis of transcriptional activity. Nucleic Acids Research 15, 8041-8056.

Gross, R., ARIcò, B. \& RAppuoli, R. (1989). Families of bacterial signal-transducing proteins. Molecular Microbiology 3, 1661-1667.

hara, O., Anzai, H., Imai, S., Kumada, Y., Murakami, T., Itoh, R., Takano, E., Satoh, A. \& Nagaoka, K. (1988). The bialaphos biosynthetic genes of Streptomyces hygroscopicus: cloning and analysis of the genes involved in the alanylation step. Journal of Antibiotics 41, 538-547.

Hidaka, T., SeTo, H. \& Imai, S. (1989). Biosynthetic mechanism of C$P$ bond formation. Isolation of carboxyphosphonoenolpyruvate and its conversion to phosphinopyruvate. Journal of the American Chemical Society 111, 8012-8013.

Hopwood, D. A., BibB, M. J., Chater, K. F., Kieser, T., Bruton, C. J., Kieser, H. M., Lydiate, D. J., Smith, C. P., W ARD, J. M. \& SCHREMPF, H. (1985). Genetic Manipulation of Streptomyces. A Laboratory Manual. Norwich, UK: The John Innes Foundation.

Imai, S., Seto, H., Sasaki, T., Turuoka, T., Ogawa, H., Satoh, A., INOUYE, S., NidA, T. \& OtAKe, N. (1984). Studies on the biosynthesis of bialaphos (SF1293). 4. Production of phosphonic acid derivatives 2-hydroxyethylphosphonic acid, hydroxymethylphosphonic acid and phosphonoformic acid by blocked mutants of Streptomyces hygroscopicus SF-1293 and their roles in the biosynthesis of bialaphos. Journal of Antibiotics 37, 1505-1508.

imai, S., Seto, H., Sasaki, T., Tsuruoka, T., Ogawa, H., Satoh, A., Inouye, S., NiIDa, T. \& Otake, N. (1985). Studies on the biosynthesis of bialaphos (SF1293). 6. Production of $N$-acetyldemethylphosphinothricin and $N$-acetylbialaphos by blocked mutants of Streptomyces hygroscopicus SF-1293 and their roles in the biosynthesis of bialaphos. Journal of Antibiotics 38, 687-690.

JANSSEN, G. R., WARD, J. M. \& BIBB, M. J. (1989). Unusual transcriptional and translational features of the aminoglycoside phosphotransferase gene $(a p h)$ from Streptomyces fradiae. Genes and Development 3, 415-429.

KatZ, E., Thompson, C. J. \& Hopwood, D. A. (1983). Cloning and expression of the tyrosinase gene from Streptomyces antibioticus in Streptomyces lividans. Journal of General Microbiology 129, 27032714.

Kondo, Y., Shomura, T., Ogawa, Y., Tsuruoka, T., Watanabe, H., Totsukawa, K., Suzuki, T., Moriyama, C., Yoshida, J., InouYe, S. \& NiIDA, T. (1973). Studies of a new antibiotic SF1293. I. Isolation and physicochemical and biological characterization of SF1293 substances. Science Reports of Meiji Seika Kaisha 13, 34-41.

Kumada, Y., Anzal, H., Takano, E., Murakami, T., Hara, O., Itoh, R., Imai, S., Sato, A. \& Nagaoka, K. (1988). The bialaphos resistance gene (bar) plays a role in both self-defense and bialaphos biosynthesis, in Streptomyces hygroscopicus. Journal of Antibiotics 41, $1838-1845$

Leu, W.-M., Wu, S.-Y., LiN, J.-J., Szecheng, J. L. \& Lee, Y.-H. W. (1989). Analysis of the promoter region of the melanin locus from Streptomyces antibioticus. Gene 84, 267-277.

Lomovskaya, N. D., Mkrtumian, N. M., Gostimskaya, N. L. \& DANILENKo, V. N. (1972). Characterization of the temperate actinophage $\phi \mathrm{C} 31$ isolated from Streptomyces coelicolor A3(2). Journal of Virology 9, 258-262.

Malpartida, F. \& HopwoOd, D. A. (1984). Molecular cloning of the whole biosynthetic pathway of a Streptomyces antibiotic and its expression in a heterologous host. Nature, London 309, 462-464.

Murakami, T., Anzai, H., Imai, S., Satoh, A., Nagaoka, K. \& THOMPSON, C. J. (1986). The bialaphos biosynthetic genes of Streptomyces hygroscopicus: molecular cloning of the gene cluster. Molecular and General Genetics 205, 42-50.

Ogawa, H., ImaI, S., Satoh, A. \& Kolima, M. (1983a). An improved method for the preparation of Streptomyces and Micromonospora protoplasts. Journal of Antibiotics 36, 184-186.

Ogawa, H., Imai, S., Shimizu, T. S., Satoh, A. \& Kojima, M. (1983b). Cosynthesis and protoplast fusion by mutants of bialaphos (AMPBA) producing Streptomyces hygroscopicus. Journal of Antibiotics 36, 1040-1044. 
Omura, S., Hinotozawa, K., Imamura, N. \& Murata, M. (1984). The structure of phosalacine, a new herbicidal antibiotic containing phosphinothricin. Journal of Antibiotics 37, 939-940.

Seno, E. T. \& BaLtZ, R. H. (1989). Structural organization and regulation of antibiotic biosynthesis and resistance genes in actinomycetes. In Regulation of Secondary Metabolism in Actinomycetes, pp. 1-48. Edited by S. Shipiro. Boca Ration, Fla.: CRC Press.

Seno, E. T., Bruton, C. J. \& Chater, K. F. (1984). The glycerol utilization operon of Streptomyces coelicolor: genetic mapping of $\mathrm{gyl}$ mutations and the analysis of cloned gyl DNA. Molecular and General Genetics 193, 119-128.

Seto, H., Imai, S., Tsuruoka, T., Ogawa, H., Satoh, A., Sasaki, T. \& OTAKE, N. (1983a). Studies on the biosynthesis of bialaphos (SF1293). 3. Production of phosphinic acid derivatives, MP-103, MP0104, and MP-105, by a blocked mutant of Streptomyces hygroscopicus SF-1293 and their roles in the biosynthesis of bialaphos. Biochemical and Biophysical Research Communications 111, 10081014.

Seto, H., Sasaki, T., Imai, S., Tsuruoka, T., Ogawa, H., Satoh, A., INOUYe, S., NidDa, T. \& OtAKE, N. (1983b). Studies on the biosynthesis of bialaphos (SF-1293). 2. Isolation of the first natural products with $\mathbf{C}-\mathrm{P}-\mathrm{H}$ bond and their involvement in the $\mathrm{C}-\mathrm{P}-\mathrm{C}$ bond formation. Journal of Antibiotics 36, 96-98.

Seto, H., Imai, S., Sasaki, T., Shimotohno, K., Tsuruoka, T., Ogawa, H., Satoh, A., INOUYe, S., Nidda, T. \& Otake, N. (1984). Studies on the biosynthesis of bialaphos (SF-1293). 5. Production of 2-phosphinomethylmalic acid, an analogue of citric acid, by Streptomyces hygroscopicus SF-1293 and its involvement in the biosynthesis of bialaphos. Journal of Antibiotics 37, 1509-1511.

Sherman, D. H., Malpartida, F., BibB, M. J., Kieser, H., BibB, M. J. \& HOPWOOD, D. A. (1989). Structure and deduced function of the granaticin-producing polyketide synthetase gene cluster of Streptomyces violaceoruber Tü22. EMBO Journal 8, 2717-2725.

Shimotohno, K., Seto, H., Otake, N., Imai, S. \& Satoh, A. (1986). Studies on the biosynthesis of bialaphos (SF-1293). 7. The absolute configuration of 2-phosphinomethylmalic acid, a biosynthetic intermediate of bialaphos. Journal of Antibiotics 39, 1356-1359.

Smith, D. J., Burnham, M. K. R., Bull, J. H., Hodgson, J. E., Ward, J. M., Browne, P., Brown, J., Barton, B., EARL, A. J. \& TURner, G. (1990). $\beta$-Lactam antibiotic biosynthetic genes have been conserved in clusters in prokaryotes and eukaryotes. EMBO Journal 9, 741-747.

Stock, J. B., Stock, A. M. \& Mortonen, J. M. (1990). Signal transduction in bacteria. Nature, London 344, 395-400.

Strauch, E., Wohlleben, W. \& Pühler, A. (1988). Cloning of a phosphinothricin $\mathrm{N}$-acetyltransferase gene from Streptomyces viridochromogenes Tü494 and its expression in Streptomyces lividans and Escherichia coli. Gene 63, 65-74.

Thompson, C. J., Movva, N. R., Tizard, R., Crameri, R., Davies, J. E., LAUwereys, M. \& BotTerman, J. (1987). Characterization of the herbicide-resistance gene bar from Streptomyces hygroscopicus. EMBO Journal 6, 2519-2523.

VöGTLI, M. \& HÜrTER, R. (1987). Characterisation of the hydroxystreptomycin phosphotransferase gene (sph) of Streptomyces glaucescens: nucleotide sequence and promoter analysis. Molecular and General Genetics 208, 195-203.

WARD, J. M., JANSSEN, G. R., Kieser, T., BibB, M. J., Buttner, M. J. \& BIBB, M. J. (1986). Construction and characterisation of a series of multi-copy promoter-probe plasmid vectors for Streptomyces using the aminoglycoside phosphotransferase gene from $\mathrm{Tn} 5$ as indicator Molecular and General Genetics 203, 468-475. 